\title{
CORRESPONDENCE Fibrinolytic therapy for COVID-19: a review of case series
}

\author{
Hong-Long $\mathrm{Ji}^{1,2}$, Yuling Dai ${ }^{3}$ and Runzhen Zhao ${ }^{1}$ \\ Acta Pharmacologica Sinica (2022) 43:2168-2170; https://doi.org/10.1038/s41401-021-00827-w
}

Thromboembolism is the leading cause of mortality in COVID-19 patients. Thrombi, including pulmonary embolism (PE) and deep vein thrombosis (DVT), range from minor sequelae to fatal complications of SARS-CoV-2 infection [1]. Individuals with preexisting conditions are more likely to develop thrombi and have poor outcomes [2]. The guidelines from professional societies for the use of fibrinolytic therapy (FT) in COVID-19 are inconsistent [3]. The outcomes of FT for ARDS (acute respiratory distress syndrome) associated with COVID-19 have not been clarified to date. We have summarized 105 COVID-19 patients treated with alteplase (tPA). IPA was applied for thrombolytic (fibrinolytic, generally after the failure of heparin), salvage (rescue for gravely ill patients), or prophylactic therapies for those with a potential of thrombosis [4]. We have compared the morbidity, mortality, complications, laboratory tests of COVID-19 patients with ARDS versus those without ARDS (nonARDS), and adverse events of fibrinolytic therapy.

\section{METHODS}

This pooled study aimed to summarize all reported case series of fibrinolytic therapy for COVID-19. IRB approval and informed consent were not required. Clinical features of all 105 individual cases are presented in Table 1, and additional details are shown in the online supplement. Outcomes were ICU admission, discharge to the general ward, in-hospital death, or discharge home. One-Way ANOVA for continuous variables and $x^{2}$ tests for categorical variables were conducted using R (v4.0.3) and Prism 9 with a two-sided level of significance $P<0.05$. The results were graphed using the ggplot2 package.

\section{RESULTS}

Recipients were from 11 countries and represented multiple ethnicities. The average age was $58.7 \pm 14.1$ year. There was an insignificant difference in age and gender between ARDS and nonARDS groups. More respiratory diseases were reported for the ARDS group. In contrast, no other comorbidities were different between the two groups (Table 1). PE associated with ARDS patients was a predominant indication for tPA, while hypoxic stroke and myocardial infarction of non-ARDS was for the non-ARDS group. The total dose of tPA and frequency used for salvage therapy was insignificant between ARDS and non-ARDS groups. Few adverse events were reported.
Plasma D-dimer and fibrinogen levels of patients who died were higher than those who survived. ICU patients had a higher PTT (Table 1). WBC, PTT, fibrinogen, and LDH levels were elevated up to 3-fold in ARDS patients compared with non-ARDS. Further, WBC count was lower among patients who recovered (Fig. 1). Mortality was higher among patients with ARDS, as was the need for ICU care. Fewer patients with ARDS were discharged home. The overall mortality was much high for the patients who developed PE (39.7\%), septic shock (63.6\%), acute kidney injury $(75.0 \%)$, MOF (85.7\%), and cardiac arrest and heart failure (72.7\%). Of ARDS patients, $42 \%$ had multiple pulmonary emboli or thrombi. The incidence of acute kidney injury, respiratory failure, and tachycardia/fibrillation was much greater for ARDS patients.

\section{DISCUSSION}

tPA was administered generally upon the failure of anticoagulation therapy, including heparin, aspirin, enoxaparin. Antivirus medicines, antibiotics, and supportive care with various dose, duration, route, and combinations were applied to some patients based on their conditions. The finding of high mortality and the need for ICU care among the COVID-19-associated ARDS may be related to pre-existing respiratory diseases and inflammation [5]. The fatal complications of COVID-19, including PE, shock, cardiac failure, kidney injury, and MOF, further reduce the survival rate. In addition to WBC, increased plasma PTT and fibrinogen levels could signify a poor prognosis. Considering few adverse events associated with fibrinolytic therapy, early and the local application of tPA and others (i.e., uPA, plasminogen, plasmin) combined with precisely anti-inflammation interventions to target case-dependent cytokines and chemokines could improve the survival of COVID-19 patients with critically ARDS. By comparison, fibrinolytic therapy for COVID-19 patients without ARDS or other severe complications significantly improves the outcomes [2]. The main limitation of retrospective study was the scarcity of randomized controlled groups and standardized procedures for laboratory tests, clinical readouts, and fibrinolytic therapy. The randomized controlled trials designed to test the benefits of fibrinolytic therapy are recruiting patients. Nevertheless, this pooled study has implications for the stratification and prognosis of COVID-19-associated ARDS.

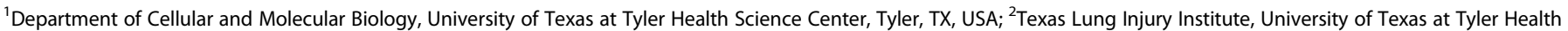
Science Center, Tyler, TX, USA and ${ }^{3}$ Department of Epidemiology, University of Alabama at Birmingham, Birmingham, AL, USA

Correspondence: Hong-Long Ji (james.ji@uthct.edu)
}

Received: 23 September 2021 Accepted: 17 November 2021

Published online: 10 December 2021 
Table 1. Comparison of ARDS and non-ARDS patients treated with tPA.

\begin{tabular}{|c|c|c|c|c|}
\hline & All cases & Non-ARDS & ARDS & $P$ value \\
\hline \multicolumn{5}{|c|}{ Gender (total: 33 for non-ARDS vs 58 for ARDS) } \\
\hline Female & 27 & $10(30.3 \%)$ & $17(29.3 \%)$ & $0.92^{\mathrm{a}, \mathrm{c}}$ \\
\hline \multicolumn{5}{|c|}{ Comorbidities (total: 26 for non-ARDS vs 37 for ARDS) } \\
\hline Hypertension & 33 & $16(61.5 \%)$ & 17 (46.0\%) & $0.50^{\mathrm{a}}$ \\
\hline All cardiovascular illness: Thrombosis & $\begin{array}{l}37 \\
28\end{array}$ & $\begin{array}{l}16(61.5 \%) \\
16(61.5 \%)\end{array}$ & $\begin{array}{l}21(56.8 \%) \\
12(32.4 \%)\end{array}$ & $\begin{array}{l}0.85^{\mathrm{a}} \\
0.70\end{array}$ \\
\hline Obesity & 14 & $3(11.5 \%)$ & $11(29.7 \%)$ & $0.17^{\mathrm{a}}$ \\
\hline $\begin{array}{l}\text { All respiratory disease: } \\
\text { Respiratory failure }\end{array}$ & $\begin{array}{l}29 \\
10\end{array}$ & $\begin{array}{l}6(23.1 \%) \\
2(7.7 \%)\end{array}$ & $\begin{array}{l}23(62.2 \%) \\
8(21.6 \%)\end{array}$ & $\begin{array}{l}0.05^{* * a} \\
0.002\end{array}$ \\
\hline$>3$ comorbidities & 38 & $14(53.8 \%)$ & $24(64.9 \%)$ & $0.66^{\mathrm{a}}$ \\
\hline \multicolumn{5}{|c|}{ Indications for tPA (total: 31 for non-ARDS and 45 for ARDS) } \\
\hline PE & 58 & 7 & 51 & $0.001^{\mathrm{a}}$ \\
\hline Stroke and STEMI & 25 & 24 & 1 & $<0.00001^{\mathrm{a}}$ \\
\hline \multicolumn{5}{|l|}{ Laboratory tests } \\
\hline WBC $\left(4.5 \times 10^{9}-11 \times 10^{9} / \mathrm{L}\right)$ & $22(18 / 4)$ & $9.3 \pm 2.6$ & $16.6 \pm 9.8$ & $0.005^{* * * \mathrm{~b}}$ \\
\hline Lymphocyte $\left(0.9 \times 10^{9}-2.9 \times 10^{9} / \mathrm{L}\right)$ & $15(14 / 1)$ & $1.7 \pm 1.2$ & 0.66 & - \\
\hline Platelet $\left(<150 \times 10^{3} / \mathrm{mL}\right)$ & $35(21 / 14)$ & $241.7 \pm 84.4$ & $249.3 \pm 120.4$ & $0.82^{\mathrm{b}}$ \\
\hline PTT (60-70 s) & $18(13 / 5)$ & $16.4 \pm 9.0$ & $32.7 \pm 3.5$ & $0.004^{* * * * \mathrm{~b}}$ \\
\hline APTT (30-40 s) & $20(18 / 2)$ & $32.7 \pm 8.9$ & $36.50 \pm 2.12$ & 0.65 \\
\hline Fibrinogen $(2-4 \mathrm{~g} / \mathrm{L})$ & $38(17 / 21)$ & $1.0 \pm 2.3$ & $2.7 \pm 2.9$ & $0.04^{* * b}$ \\
\hline D-dimer $(<0.5 \mu \mathrm{g} / \mathrm{mL})$ & $56(24 / 32)$ & $10.7 \pm 21.9$ & $13.4 \pm 22.2$ & $0.62^{\mathrm{b}}$ \\
\hline Discharged home & 25 & $16(57.1 \%)$ & $9(12.9 \%)$ & $0.001^{* * * * c}$ \\
\hline \multicolumn{5}{|c|}{ Complications (total: 23 for non-ARDS vs 33 for ARDS) } \\
\hline Sepsis & 3 & $0(0 \%)$ & $3(9.1 \%)$ & $0.15^{\mathrm{a}}$ \\
\hline Shock & 9 & $2(8.7 \%)$ & $7(21.2 \%)$ & $0.27^{\mathrm{a}}$ \\
\hline Multiple organ failure & 7 & $1(4.3 \%)$ & $6(18.2 \%)$ & $0.164^{\mathrm{a}}$ \\
\hline Multiple PE \& thrombus & 14 & $0(0 \%)$ & $14 / 0(42.4 \%)$ & $0.0003^{* * * a}$ \\
\hline Cardiac arrest/heat failure & $5 / 5$ & $1 / 2(4.3 \% / 8.7 \%)$ & 4/3 (12.1\%/9.1\%) & $0.35^{\mathrm{a}} / 0.32$ \\
\hline Respiratory failure & 6 & $0(0 \%)$ & $6(18.2 \%)$ & $0.03^{* * a}$ \\
\hline Acute kidney injury & 5 & $0(0 \%)$ & $5(15.2 \%)$ & $0.04^{* a}$ \\
\hline Tachycardia/fibrillation & 8 & $6(26.1 \%)$ & $2(6.1 \%)$ & $0.05^{* a}$ \\
\hline
\end{tabular}

Mean \pm SD.

TPA tissue-like plasminogen activator, WBC white blood cell, $P T T$ partial thromboplastin time, $a P T T$ activated partial thromboplastin time, $L D H$ lactate dehydrogenase, $C R P$ C-reactive protein.

${ }^{a} \chi^{2}$ test.

bone-Way ANOVA with a two-sided $<0.05$.

confirmed with $\mathrm{R}$.

${ }^{*} P<0.1 ;{ }^{*} P \leq 0.05 ; * * * P<0.01,{ }^{* * *} P \leq 0.001$.

Footnote: Original case reports were with the following PMIDs: 33043052, 32962933, 32735730, 32267998, 33352323, 33133702, 33403100, 32427773,

$32497796,32663257,32427774,33634156,32886934,32425320,32508062,32445784,32763101,32780853,32948531,32634813,32513452,32526545$,

33083223, 33066885, 32414622, 32656711, 32907873, 32835021, 32835024, 32706216, 32675154, 32432162, 32864630, $32917441,32386986,32952405$.

$\xi$ slight hemorrhage was reported in intramuscle, intracranium, upper gastrointestinal tract, mouth, and femur. 

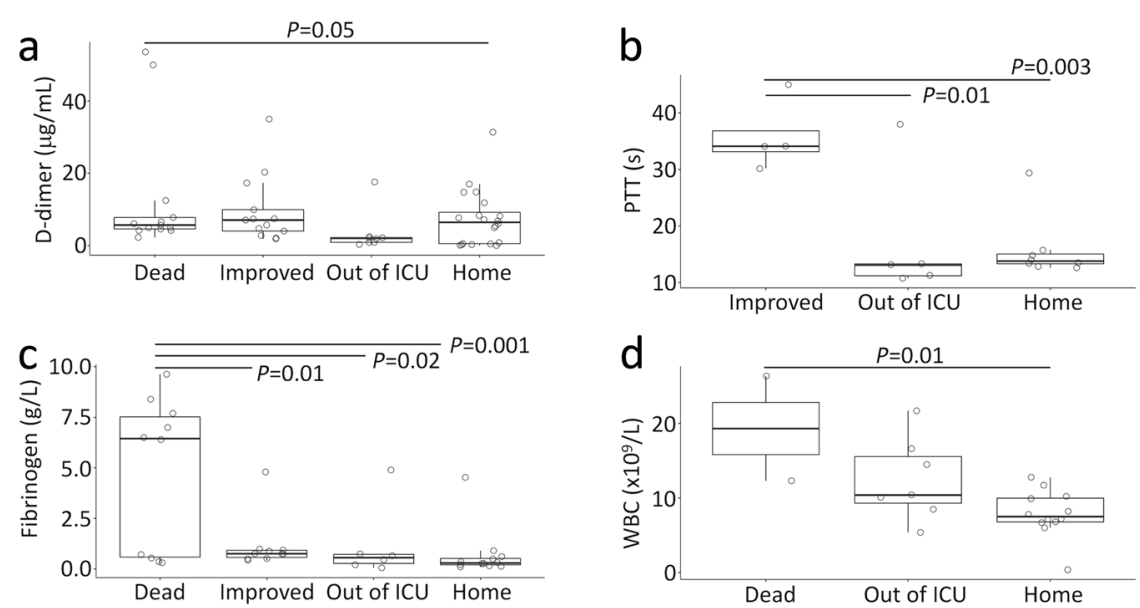

Fig. 1 Trend of outcomes against fibrinolysis and inflammation. D-dimer (a), PTT (b), fibrinogen (c), and WBC (d) levels prior to fibrinolytic therapy were compared for four outcomes of all patients. The outcome without sufficient patients $(n<3)$ was removed for PTT (c) and WBC (d). The full names of abbreviations were described in Table 1.

\section{ACKNOWLEDGEMENTS}

This study was supported by NIH grant HL134828.

\section{AUTHOR CONTRIBUTIONS}

HLJ had full access to all of the data in the study and takes responsibility for the integrity of the data and the accuracy of the data analysis. Concept and design: HU. Acquisition, analysis, or interpretation of data: RZ, YD, HLJ. Drafting of the manuscript: RZ, HLJ. Critical revision of the manuscript for important intellectual content: RZ, HU. Statistical analysis: YD, HLJ. Obtained funding: HLJ and RZ. Administrative, technical, or material support: RZ, YD, HLJ. Supervision: HLJ.

\section{ADDITIONAL INFORMATION}

Competing interests: The authors declare no competing interests.

\section{REFERENCES}

1. Gu SX, Tyagi T, Jain K, Gu VW, Lee SH, Hwa JM, et al. Thrombocytopathy and endotheliopathy: crucial contributors to COVID-19 thromboinflammation. Nat Rev Cardiol. 2021;18:194-209.

2. Ji HL, Zhao R, Matalon S, Matthay MA. Elevated plasmin(ogen) as a common risk factor for COVID-19 susceptibility. Physiol Rev. 2020;100:1065-75.

3. Whyte CS, Morrow GB, Mitchell JL, Chowdary P, Mutch NJ. Fibrinolytic abnormalities in acute respiratory distress syndrome (ARDS) and versatility of thrombolytic drugs to treat COVID-19. J Thromb Haemost. 2020;18:1548-55.

4. Douin DJ, Shaefi S, Brenner SK, Gupta S, Park I, Wright FL, et al. Tissue plasminogen activator in critically III adults with COVID-19. Ann Am Thorac Soc. 2021;18:1917-21. https://doi.org/10.1513/AnnalsATS.202102-202127RL.

5. Zhao R, Su Z, Komissarov AA, Liu SL, Yi G, Idell S, et al. Associations of D-Dimer on admission and clinical features of COVID-19 patients: a systematic review, metaanalysis, and meta-regression. Front Immunol. 2021;12:691249. 